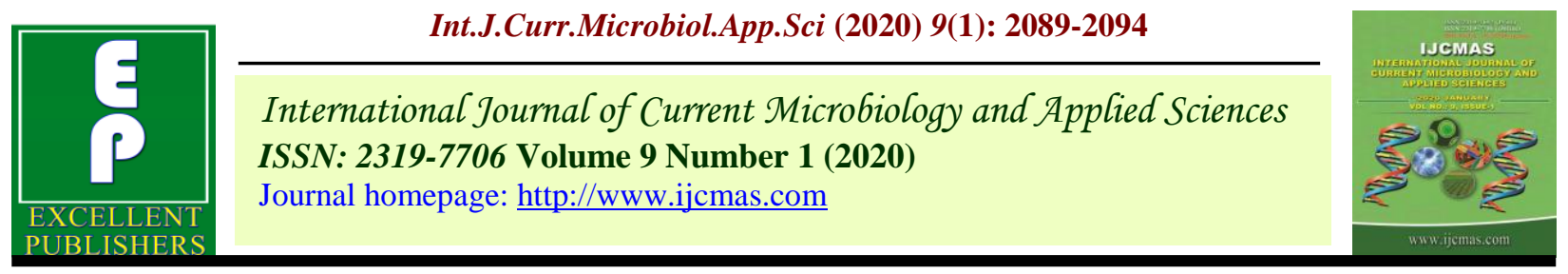

Original Research Article

https://doi.org/10.20546/ijcmas.2020.901.237

\title{
SRI-Finger Millet Cultivation a Case Study in Tumakuru District, India
}

\author{
Somashekhar $^{1 *}$ and N. Loganandhan ${ }^{2}$ \\ ${ }^{1}$ Plant Breeding, ICAR-Krishi Vigyan Kendra, Gonikoppal, Kodagu district-571213, India \\ ${ }^{2}$ ICAR-Krishi Vigyan Kendra, Hirehalli, Tumakuru district-572168, India \\ *Corresponding author
}

\begin{tabular}{|l|}
\hline Ke y w o r d s \\
SRI-Finger Millet, \\
Cultivation, Seed \\
sorting, Priming and \\
treatment
\end{tabular}

\section{A B S T R A C T}

System of Finger millet intensification or SRI-finger millet cultivation is a method of cultivating finger millet by applying cultivation principles adopted in SRI (System of Rice Intensification) in order to get higher productivity. This method is also called as Guli type of Planting. This POP developed for SRIFinger Millet is an integration of the farmers' practice and standard practices of finger millet cultivation along with two levels of two doses of fertilizers. Here an effort has been made to know the potentiality of this finger millet cultivation to increase the productivity of the Ragi crop was taken during 2015-16 kharif season at KVK Farm Hirehalli of Tumakauru district in Karnataka state. Tillering starts after the first weeding. On an average 8-10 tillers per hill emerge, out of which 6-8 become productive and bear the fingers. More number of Tillers was observed in T4- 60 x $30 \mathrm{~cm}$ with $100 \%$ RDF - single seedling followed by T3 $-60 \times 30 \mathrm{~cm}$ with 50\% RDF and finally highest Ragi yield was obtained in the same treatment T4 with quantity of $2452 \mathrm{~kg} / \mathrm{ha}$ followed by $2361 \mathrm{~kg} / \mathrm{ha}$ in T3.

\section{Introduction}

Millets are important but underutilized crops in tropical and semiarid regions of the world due to their greater resistance to pests and diseases, good adaption to a wide range of environment and their good yield of production, can withstand significant levels of salinity, short growing season, resistant to water logging, drought tolerant, requires little inputs during growth and with increasing world population and decreasing water supplies represents important crops for future human use. The drought tolerance of finger millet may be attributed to an efficient antioxidant potential and increased signal perception. Being as hardy crop it is relatively easy to grow finger millet under stressful regimes, without hampering the net productivity (Chandrasekara and Shahidi, 2010).

Finger millet is milled with the testa which is generally rich in dietary fiber and 
micronutrients to prepare flour and the whole meal is utilized in the preparation of traditional foods, such as roti (unleavened breads), ambali (thin porridge) and mudde (dumpling) (Devi et al., 2014).

The productivity of finger millet can be increased by applying judicious combination of organic and inorganic fertilizers along with the scientific validation of indigenous technical knowledge of the farmers, which helps to improve the soil health as well as the productivity of finger millet (Ramamurthy et al., 1993). Guni method has been a best example for farmer's wide knowledge in cultivation methods in ragi whereas single seedling method of SRI cultivation in case of paddy was found more profitable, hence combination of these two potential methods are tested in different levels inorganic fertilizers. In guni method, land preparation is as usual for crop production and then they create a grid similar to that with SRI method of paddy cultivation. Here an effort was made to know the effect of both inorganic fertilizer as well as intensified method of ragi cultivation and compared with farmers method of ragi cultivation.

\section{Materials and Methods}

A large number of varieties have been evolved for cultivation ranging from short duration (90days) to long duration (120 days). For cultivating in this method it is always better to go for Region specific high yielding variety. In this case a medium duration popular variety ML-365 where in the last few years this variety is has shown better yield performance consistently in the farmers' field in Tumakuru district. Farmer can also use the local variety readily available. The seed rate under SRI-Finger millet is $0.25 \mathrm{~kg}$ per acre for spacing of $25 \mathrm{~cm} \times 25 \mathrm{~cm}$ as compared to $4.0 \mathrm{~kg} / \mathrm{acre}$ in conventional method. Transplanting at different spacing levels i.e. $30 \mathrm{~cm} \times 30 \mathrm{~cm}, 30 \times 60 \mathrm{~cm}$ with single seedling and $20 \mathrm{~cm} \times 30 \mathrm{~cm}$ with three seedlings were experimented and tested at both $100 \%$ RDF and $50 \%$ RDF. The field trial was laid out in a randomized complete block design with three replications and 6 treatments combinations viz., T1- $30 \times 30 \mathrm{~cm}$ with 50\% RDF- single seedling, T2- $30 \times 30$ cm with 100\% RDF - single seedling, T3- 60 x $30 \mathrm{~cm}$ with $50 \%$ RDF - single seedling, T4$60 \times 30 \mathrm{~cm}$ with $100 \%$ RDF - single seedling, T5- $20 \times 30 \mathrm{~cm}$ with 50\% RDF-three seedlings and T6- $20 \times 30 \mathrm{~cm}$ with $100 \%$ RDF- three seedlings

\section{Seed sorting, priming and treatment}

Brine water treatment is done for separation of chaffy/ half-filled grains and to get bold and healthy seeds. After brine water treatment, the healthy seeds are again washed with normal water. Additionally, Seeds are treated with biofertilizers like Microbial consortia to treat the seed with microbes like Azospirillum (N-fixing) and PSM (Psolubilizing)@25 g/kg of seed before sowing in order to ensure better nutrient availability to the plant.

\section{Nursery raising}

Raised nursery bed is prepared by mixing soil and compost in 2:1 ratio. For 1 acre of main field $250 \mathrm{~g}$ of treated seeds are sown in $40 \mathrm{~m} 2$ nursery area. After sowing, $15 \mathrm{~kg}$ of vermicompost/powdered FYM is spread over the bed in a thin layer and covered with straw. Then the seed bed is watered once in a day by rose-cane. After 8-12 days in kharif season the seedlings attain two leaf stage and become ready for transplantation.

\section{Land preparation}

The land should be ploughed thoroughly three to four times to make the soil well pulverized. As per the availability, well decomposed compost and de-oiled cake are 
applied during land preparation. Compost @ 40 quintals/acre and neem cake @ 50 kg/acre has been proved beneficial. Sprouted finger millet seeds Seedling ready to transplant Eleusine coracana (Family : Poaceae) Growing Crops with SRI Principles were taken up.

\section{Transplanting}

Transplanting is done with seedlings of twoleaf stage. As in SRI (paddy) transplanting in SRI finger millet is done with mass of soil attached to the root, without root injury and within half an hour of uprooting from the nursery. Single seedling is transplanted with a spacing of T1-30 cm x $30 \mathrm{~cm}, \mathrm{~T} 2-60 \mathrm{~cm} \times 30$ $\mathrm{cm}, \mathrm{T} 3-20 \times 30 \mathrm{~cm}$ Farmers Practice (2 to 3 seedlings per hill).

\section{Inter cultivation (Weeding)}

First weeding is done within 20 days after transplanting with a rotary weeder. Second weeding is done manually by hoeing at 40 DAT. These two intercultural operations are sufficient to keep the field weed free and ensure root aeration.

\section{Water management}

Finger millet grown in Kharif does not require irrigation. "Tillering, panicle initiation and grain development stages are sensitive to water stress". Finger millet cannot withstand water logging. The field should be drained out in Kharif to avoid standing water.

\section{Harvesting and threshing}

Ear heads are heaped for three to four days to be cured and threshed with conventional beating with sticks or by bullock treading " At certain places, under rainfed condition, the whole plant with the ear head is cut and threshed.

\section{Results and Discussion}

The results of the present investigation revealed that, Effect of different spacing and fertilizers levels on growth significantly influenced the growth and growth attributes of finger millet. Spacing of 60 x $30 \mathrm{~cm}$ with single seedlings $+100 \%$ RDF significantly increased the plant height $(84.51 \mathrm{~cm})$ at 60 DAT which was significantly on par with spacing of $60 \times 30 \mathrm{~cm}+50 \% \operatorname{RDF}(81.4 \mathrm{~cm})$ and spacing of $30 \times 30 \mathrm{~cm}+100 \% \mathrm{RDF}$ (78.21) has shown significantly lower plant height was recorded in farmers practices with both $20 \times 30 \mathrm{~cm}+100 \%$ RTF (T6) and 50\% RTF (T5) (Table 1).

The results for other growth parameters number of leaves and crop growth rate has also shown same trend as of above trait. Increased plant height and number of leaves might be due to wider spacing with higher fertilizer levels resulted in less competition between plants for solar radiation, space and increased supply of nutrients and efficient utilization helps in better growth compared to UAS package of practices. These results corroborate the findings of Chittapur et al., (1994), Muthukrishnan and Subramanian (1980) and Hanumantha Rao et al., (1982).

Planting at $60 \times 30 \mathrm{~cm}$ with $100 \% \mathrm{RDF}$ recorded significantly higher number of tillers (10.17tillers per hill) followed by same spacing $+50 \%$ RDF (8.83 tillers per hill). Whereas, farmers practices resulted in significantly lower number of tiller per hill at both dose of fertlizer (Table 2). The higher number of tillers at wider spacing intercepted more of solar radiation, water and increased nutrient availability helped to produce significantly higher number of tillers. Again less competition between plants due to wider space allowed the individual plants to develop massive root system. 
Table.1 Plant height $(\mathrm{cm})$ and number of leaves per plant at 60 DAT growth stage of finger millet as influenced by spacing and levels of spacing

\begin{tabular}{|c|c|c|c|c|}
\hline $\begin{array}{c}\text { Sl } \\
\text { No. }\end{array}$ & Treatment & $\begin{array}{c}\text { Plant } \\
\text { Height } \\
\text { (cm) }\end{array}$ & $\begin{array}{c}\text { No.of } \\
\text { Leaves }\end{array}$ & $\begin{array}{l}\text { Crop Growth } \\
\text { Rate } \\
\text { (G/Sqm/Day) }\end{array}$ \\
\hline 1 & T1- $30 \times 30 \mathrm{~cm}$ with $50 \%$ RDF- single seedling & $72.46^{\mathrm{b}}$ & $38.42^{\text {cd }}$ & $4.12^{\mathrm{e}}$ \\
\hline 2 & T2- $30 \times 30 \mathrm{~cm}$ with $100 \%$ RDF - single seedling & $78.21^{\mathrm{ab}}$ & $40.16^{\mathrm{bc}}$ & $5.65^{\mathrm{c}}$ \\
\hline 3 & T3- $60 \times 30 \mathrm{~cm}$ with 50\% RDF - single seedling & $81.40^{\mathrm{a}}$ & $42.65^{\mathrm{ab}}$ & $5.71^{b}$ \\
\hline 4 & T4- $60 \times 30 \mathrm{~cm}$ with $100 \%$ RDF - single seedling & $84.51^{\mathrm{a}}$ & $45.18^{\mathrm{a}}$ & $6.57^{\mathrm{a}}$ \\
\hline 5 & T5- $20 \times 30 \mathrm{~cm}$ with 50\% RDF-three seedlings & $62.65^{\mathrm{c}}$ & $34.50^{\mathrm{e}}$ & $4.02^{\mathrm{d}}$ \\
\hline 6 & T6- $20 \times 30 \mathrm{~cm}$ with $100 \%$ RDF- three seedlings & $66.41^{\mathrm{c}}$ & $36.12^{\text {de }}$ & $4.56^{\mathrm{d}}$ \\
\hline \multicolumn{2}{|r|}{ C.D @P=0.05 } & 6.54 & 2.82 & 0.054 \\
\hline
\end{tabular}

Table.2 Effect of spacing and levels of NPK on number of Tillers, fodder dry weight (qt/ha) and seed yield (kg/ha)

\begin{tabular}{|c|c|c|c|c|}
\hline $\begin{array}{l}\text { Sl } \\
\text { No. }\end{array}$ & Treatment & $\begin{array}{l}\text { Number } \\
\text { of Tillers }\end{array}$ & $\begin{array}{c}\text { Fodder } \\
\text { dry weight } \\
\text { (qt/ha) }\end{array}$ & $\begin{array}{c}\text { Seed yield } \\
\text { (kg/ha) }\end{array}$ \\
\hline 1 & T1- $30 \times 30 \mathrm{~cm}$ with $50 \%$ RDF- single seedling & $4.11^{\mathrm{d}}$ & $128.32^{\mathrm{e}}$ & $1919^{\mathrm{e}}$ \\
\hline 2 & T2- $30 \times 30 \mathrm{~cm}$ with $100 \%$ RDF - single seedling & $4.67^{d}$ & $134.24^{\mathrm{e}}$ & $2156^{\mathrm{c}}$ \\
\hline 3 & T3- $60 \times 30 \mathrm{~cm}$ with 50\% RDF - single seedling & $8.83^{b}$ & $204.2^{\mathrm{b}}$ & $2361^{\mathrm{b}}$ \\
\hline 4 & T4- $60 \times 30 \mathrm{~cm}$ with $100 \%$ RDF - single seedling & $10.17^{\mathrm{a}}$ & $237.45^{\mathrm{a}}$ & $2452^{\mathrm{a}}$ \\
\hline 5 & T5- $20 \times 30 \mathrm{~cm}$ with 50\% RDF-three seedlings & $4.67^{d}$ & $145.44^{\mathrm{d}}$ & $2012^{\mathrm{e}}$ \\
\hline 6 & T6- 20 x $30 \mathrm{~cm}$ with $100 \%$ RDF- three seedlings & $5.32^{\mathrm{c}}$ & $159.31^{\mathrm{c}}$ & $2085^{\mathrm{d}}$ \\
\hline \multicolumn{2}{|r|}{ C.D @P=0.05 } & 1.21 & 9.64 & 48.51 \\
\hline
\end{tabular}


Better aeration at wider spacing resulted in healthy plant growth with more tillers. These results were in conformity with the findings of Prakasha et al., (2018).

The dry matter production is the result of cumulative and complementary effect of plant height, number of leaves, leaf area, and root weight. Dry matter production differed significantly due to different spacing and NPK levels. Among the different treatments significantly higher dry matter accumulation was rerecorded at a spacing of $60 \times 30 \mathrm{~cm}+$ $100 \%$ RDF with single seedling as compared to all other treatments. The higher total dry matter production was attributed to better plant growth which resulted in higher dry matter accumulation in leaves and stem at early growth stages and better translocation to ear heads during later stages. These results are in conformity with the findings Mishra et al., (1973) (Table 2).

Higher growth parameters like higher plant, higher number of leaves, number of tillers per hill and dry matter accumulation in leaf, stem and total plant1helps in better photosynthesis and mobilization of photosynthates from source to sink thus, resulted in production of higher seed yield $(2452 \mathrm{~kg} / \mathrm{ha})$ with spacing of $60 \times 30 \mathrm{~cm}+100 \%$ RDF application (Table 2). Increase in growth indices might be due to availability of wider spacing and adequate nutrients increased the leaf area and total dry matter production and resulted in higher growth indices.

A result obtained from present investigation indicates that application of varied levels of NPK fertilizers with different spacing significantly influences the growth and growth attributes of finger millet. Wider spacing and adequate supply of plant nutrient helps in better photosynthesis and growth of finger millet which helps in higher seed yield. This result of the experiment confirms that wider spacing provides opportunity for the initiation of higher tillers ultimately resulting in higher yield.

\section{References}

Chandrasekara, F. Shahidi Content of insoluble bound phenolics in millets and their contribution to antioxidant capacity J. Agric. Food Chem., 58 (11) (2010), pp. 6706-6714.

Chittapur, B. M., Kulkarni, B. S., Hiremath, S. N. and Hosamani, M. M., 1994, Influence of nitrogen and phosphorus on the growth ad yield of finger millet. Indian J. Agron., 39(4): 657 - 659.

Devi, P.B., R. Vijayabharathi, S. Sathyabama, N.G. Malleshi, V.B. Priyadarisini. Health benefits of finger millet (Eleusine coracana L.) polyphenols and dietary fiber: a review J. Food Sci. Technol., 51 (6) (2014), pp. 10211040.

Hanumantharao, Y., Bapireddy, Y., Yellamanda Reddy, T. and Shankara Reddy, G. H., 1982, Effect of different levels of nitrogen, phosphorus and potassium on the growth and yield of finger millet. Andhra Agril. J., 29(1): 37-41.

Mishra, A., Patra, S. S. and Patnaik, R. N., 1973, Response of ragi to spacing and nitrogen, Indian J. Agron., 18: 264268.

Muthukrishnan, P. and Subramanian, S., 1980, Weed control in maize under graded nitrogen levels. Madras Agril. J., 67: 785-789.

Prakasha, G., K.N. Kalyana Murthy, A.S. Prathima and Rohani N. Meti. 2018. Effect of Spacing and Nutrient Levels on Growth Attributes and Yield of Finger Millet (Eleusine coracana L. Gaertn) Cultivated under Guni Planting Method in Red Sandy Loamy Soil of Karnataka, India. 
Int.J.Curr.Microbiol.App.Sci. 7(05): 1337-1343.

Ramamurthy, K., Christoper, Louduraj, A., Alagudurai, S. and Kandaswamy, O. S., 2004, Effect of crop residue management of early season legumes on the succeeding rainfed finger millet. MdrasAgril. J., 91(4-6): 180183.

\section{How to cite this article:}

Somashekhar and Loganandhan, N. 2020. SRI-Finger Millet Cultivation a Case Study in Tumakuru District, India. Int.J.Curr.Microbiol.App.Sci. 9(01): 2089-2094. doi: https://doi.org/10.20546/ijcmas.2020.901.237 